\title{
The impact of temperature and Wolbachia infection on vector competence of potential dengue vectors Aedes aegypti and Aedes albopictus in the transmission of dengue virus serotype 1 in southern Taiwan
}

Cheng-Hui Tsai ${ }^{1}$, Tien-Huang Chen ${ }^{1,2}$, Cheo Lin ${ }^{1}$, Pei-Yun Shu' ${ }^{1}$ Chien-Ling Su ${ }^{1}$ and Hwa-Jen Teng ${ }^{1 *}$

\begin{abstract}
Background: We evaluated the impact of temperature and Wolbachia infection on vector competence of the local Aedes aegypti and Ae. albopictus populations of southern Taiwan in the laboratory.

Results: After oral infection with dengue serotype 1 virus (DENV-1), female mosquitoes were incubated at temperatures of $10,16,22,28$ and $34^{\circ} \mathrm{C}$. Subsequently, salivary gland, head, and thorax-abdomen samples were analyzed for their virus titer at $0,5,10,15,20,25$ and 30 days post-infection (dpi) by real-time RT-PCR. The results showed that Ae. aegypti survived significantly longer and that dengue viral genome levels in the thorax-abdomen $\left(10^{3.25} \pm 0.53-10^{4.09} \pm 0.71\right.$ PFU equivalents $\left./ \mathrm{ml}\right)$ and salivary gland samples $\left(10^{2.67} \pm 0.33-10^{3.89} \pm 0.58 \mathrm{PFU}\right.$ equivalents/ $\mathrm{ml}$ ) were significantly higher at high temperature $\left(28-34^{\circ} \mathrm{C}\right)$. The survival of Ae. albopictus was significantly better at 16 or $28^{\circ} \mathrm{C}$, but the virus titers from thorax-abdomen $\left(10^{0.70}-10^{2.39} \pm 1.31 \mathrm{PFU}\right.$ equivalents $\left./ \mathrm{ml}\right)$ and salivary gland samples $\left(10^{0.12 \pm 0.05}-10^{1.51} \pm 0.31 \mathrm{PFU}\right.$ equivalents $\left./ \mathrm{ml}\right)$ were significantly higher at $22-28^{\circ} \mathrm{C}$. Within viable temperature ranges, the viruses were detectable after $10 \mathrm{dpi}$ in salivary glands and head tissues in Ae. aegypti and after 5-10 dpi in Ae. albopictus. Vector competence was measured in Ae. albopictus with and without Wolbachia at $28{ }^{\circ} \mathrm{C}$. Wolbachiainfected mosquitoes survived significantly better and carried lower virus titers than Wolbachia-free mosquitoes. Wolbachia coinfections (92.8-97.2\%) with wAlbA and wAlbB strains were commonly found in a wild population of Ae. albopictus.

Conclusions: In southern Taiwan, Ae. aegypti is the main vector of dengue and Ae. albopictus has a non-significant role in the transmission of dengue virus due to the high prevalence of Wolbachia infection in the local mosquito population of southern Taiwan.
\end{abstract}

Keywords: Aedes aegypti, Aedes albopictus, Temperature, Wolbachia, Dengue virus, Taiwan

\footnotetext{
*Correspondence: hjteng@cdc.gov.tw

${ }^{1}$ Center for Diagnostics and Vaccine Development, Centers for Disease

Control, Taipei 11561TaiwanRepublic of China

Full list of author information is available at the end of the article
} 


\section{Background}

Dengue fever is the most common arboviral disease in tropical and subtropical regions in the world. In recent decades, the numbers of dengue cases and countries with endemic dengue fever have dramatically increased because of global warming [1], rapid and frequent international traveling, ineffective vector control, changing life styles and unplanned urbanization [2]. The disease burden of dengue is estimated at 390 million dengue infections per year, with 96 million cases exhibiting apparent symptoms [3]. Moreover, a total of 3.9 billion people living in 128 countries have been identified as at risk for dengue virus infection [4]. In Taiwan, since 2004, outbreaks have occurred annually with peaks in 2014 and 2015 (15,492 and 43,419 indigenous cases, respectively). These local mosquito-transmitted cases were mainly found in southern Taiwan where Aedes aegypti L. and Ae. albopictus (Skuse) coexist. The former species has limited distributions in southern Taiwan, Taitung City in eastern Taiwan and the Penghu Islands. The latter species is found in islands below the altitudes of $1760 \mathrm{~m}$ above sea level [5].

Dengue outbreaks have occurred in late spring or early summer and have peaked in the fall in many countries, including Taiwan. Previous studies have found that temperature is the most important abiotic environmental factor because it affects the vector efficiency [6-8]. Viral replication and propagation speed are faster at higher temperatures. The extrinsic incubation period (EIP), the time from the initial acquisition of the dengue virus by mosquito vectors to the time of transmission to a human host ranges from 5 to 33 days at $25{ }^{\circ} \mathrm{C}$ and from 2 to 15 days at $30{ }^{\circ} \mathrm{C}$, with an average of 15 and 6.5 days, respectively [9]. Additionally, the mosquito species and strain [10], virus serotypes and genotypes [11], virus uptake quantity [6], size of adult mosquitoes [12], and Wolbachia infection [13-15] also affect dengue viral replication or limit viral transmission. Among these factors, the effect of Wolbachia is worth paying attention to due to the disease control strategy. Although the mechanism of Wolbachia-mediated pathogen interference is unclear, Wolbachia-induced, density-dependent inhibition of dengue virus in Aedes mosquitoes is temperature sensitive [16]. Therefore, some studies showed no Wolbachia effect on chikungunya virus infection [17] and dengue virus [18] in Ae. albopictus mosquitoes, but other studies showed that Wolbachia infection reduced dengue viral transmission but not the viral load [14].

Dengue is not considered an endemic disease in Taiwan. Most dengue outbreaks have originated from imported dengue cases, in which the introduced virus was transmitted to local Aedes mosquitoes in the late spring or the early summer, except for four winter outbreaks in Taiwan. These outbreaks were DENV-1 in
1987-1988, DENV-2 in 2002-2003, DENV-3 in 20092010, and DENV-1 in 2014-2015 [19]. Furthermore, an ovitrap survey from 2010 to 2011 found that Ae. aegypti mosquitoes were able to oviposit all year long in Kaohsiung City [20]. The magnitude of dengue outbreaks can reach hundreds or thousands of people in the distribution areas of Ae. aegypti. However, only clusters (less than 20 dengue cases) of DENV-1 occurred in areas without the presence of Ae. aegypti, where Ae. albopictus mosquitoes served as the transmitting vectors instead. In Taiwan, Wolbachia infection with wAlbA and wAlbB is very common in the local Ae. albopictus population but not the Ae. aegypti population [21]. Therefore, the objective of this study was to compare the vector competence of local Ae. aegypti and Ae. albopictus populations in high-risk dengue areas in southern Taiwan for DENV-1 at different incubation temperatures in the laboratory. In addition, the natural effect of Wolbachia infection on the vector competence of the local $A e$. albopictus population was also evaluated.

\section{Methods}

\section{Mosquito collection and maintenance}

Aedes aegypti and Ae. albopictus larvae and pupae were collected from a dengue high-risk area, the Chien-chen district, Kaohsiung City, in 2015 and 2016, respectively. Most collections occurred in the public domain and for any collections referred to the private sector, owners/residents were asked for permission to collect mosquitoes on their land/in their residences. The F1 adults used for the various temperature experiments, for each species, were from a single collection of larvae reared under the same conditions $\left[20-30{ }^{\circ} \mathrm{C}\right.$ with a photoperiod of $10: 14 \mathrm{~h}$ (L:D)]. Immature mosquitoes were reared in a plastic pan $(21 \times 14 \times 7 \mathrm{~cm})$ containing $450 \mathrm{ml}$ of deionized water. A sufficient amount of food (yeast extract and pig liver powder; 1:1 by weight) was provided daily. Adult mosquitoes were kept in an acrylic cage $(29 \times 20 \times 20 \mathrm{~cm})$ and were provided with a $10 \%$ sucrose solution. The first generation (F1) of these field populations was used in the following experiments. Additionally, to eliminate Wolbachia infection, adult F1 Ae. albopictus mosquitoes were fed a $1 \mathrm{mg} /$ $\mathrm{ml}$ tetracycline solution in sucrose as described previously [22]. Each generation of mosquitoes was fed with tetracycline for at least two weeks and given a blood meal, and then, eggs hatched to produce the next generation ( $F 1$ to F3). When the third generation (F3) was shown to have no infection of Wolbachia, the fourth generation (F4) was used as the Wolbachia-free mosquitoes for further experiments. To minimize the impact of antibiotic on mosquito microflora, the eighth generation (F8) was also used as the Wolbachia-free mosquitoes for giving a recovery of 2 additional generations (tetracycline using in F1-F5). 


\section{Experimental oral infection}

Two- to five-day-old female mosquitoes were deprived of sugar solution for $24 \mathrm{~h}$ prior to the oral challenge. The feeding mixture was prepared by mixing equal parts of DENV-1-infected C6/36 supernatant and human blood treated with an anticoagulant $(7 \mathrm{ml}$ of human blood:18 mg of K2EDTA) (cat. no. 367525, Becton Dickinson and Company, New Jersey, USA). The virus strains (H1030440) used in this study was the dominant strain of 2014 [19], which was isolated from blood specimens of the indigenous cases. All were harvested at virus titer of $10^{7}$ plaque forming units (PFU) per $\mathrm{ml}$ (determined by plaque assay). A high virus titer of $1.63 \times 10^{7} \mathrm{PFU} / \mathrm{ml}$ was used for the following experiments, and this titer was close to the high viral load (ranging from $1.9 \times 10^{6}$ to $4.7 \times 10^{7} \mathrm{PFU} / \mathrm{ml}$ ) of viremic patients [23]. Ten females were placed in a small paper cup $(8 \mathrm{~cm}$ diameter $\times 9.5 \mathrm{~cm}$ height) covered with fine nylon mesh. The Hemotek 5 W1 membrane feeding system (Hemotek Ltd., Lancashire, UK) was used and Ae. aegypti and Ae. albopictus mosquitoes were allowed to feed for $1 \mathrm{~h}$. The fed mosquitoes were then held in a growth chamber at 10,16, 22, 28 or $34{ }^{\circ} \mathrm{C}$, with $75 \%$ relative humidity $(\mathrm{RH})$. Cotton soaked in a $10 \%$ sugar solution was provided on the mesh and changed every 2 days. Mosquitoes were frozen at 0,5 , $10,15,20,25$, and 30 day intervals as knockouts. Then, the heads, salivary glands and thorax-abdomens were dissected for samples and stored at $-80{ }^{\circ} \mathrm{C}$ until processing for virus or Wolbachia detection.

\section{Viral detection and titration}

Individual samples (salivary glands, head, thoraxabdomen, midgut or fat-body) were homogenized and purified by centrifugation. Viral RNA $(70 \mu \mathrm{l})$ was extracted from $140 \mu \mathrm{l}$ of sample suspension using the QIAamp Viral RNA Mini Kit (cat. no. 52,906, Qiagen, Hilden, Germany) according to the manufacturer's instructions. Amplification by RT-PCR was performed using the LightCycler quantitative PCR system (Roche Applied Science, California, USA). Samples were assayed in a $50 \mu \mathrm{l}$ reaction mixture containing $10 \mu \mathrm{l}$ of sample RNA and optimal concentrations of the primers using the QuantiTect SYBR Green RT-PCR Kit (cat. no. 204, 243, Qiagen, Hilden, Germany). Type I dengue virusspecific primers DN-F (5'-CAA TAT GCT GAA ACG CGA GAG AAA-3') and D1-R (5'-CGC TCC ATA CAT CTT GAA TGA G-3') [24], were used for realtime RT-PCR, and the products were expected to be $193 \mathrm{bp}$. The thermal profile consisted of a $30 \mathrm{~min}$ reverse transcription step at $50{ }^{\circ} \mathrm{C}$, followed by $15 \mathrm{~min}$ of Taq polymerase activation at $95{ }^{\circ} \mathrm{C}$; these steps were then followed by 45 cycles of PCR $\left(94{ }^{\circ} \mathrm{C}\right.$ for $15 \mathrm{~s}$, annealing temperature $55^{\circ} \mathrm{C}$ for $30 \mathrm{~s}$, and $72{ }^{\circ} \mathrm{C}$ for $20 \mathrm{~s}$ ).
Additionally, serial ten-fold dilutions of dengue virus (strain H1030440) were performed with an initial viral load of $1.63 \times 10^{7} \mathrm{PFU} / \mathrm{ml}$. Each dilution was added to $140 \mu \mathrm{l}$ of the salivary glands, heads, thorax-abdomens, midguts and fat-body sample suspension of one noninfected Ae. aegypti or Ae. albopictus female mosquito to estimate the virus titers in the salivary glands, heads, thorax-abdomens, midguts and fat-body of orally infected mosquitoes. The virus titer standard curve was generated by real-time RT-PCR. The linear regressions of the $\mathrm{Ct}$ value $(\mathrm{Y})$ against $\log$ (viral load, $\mathrm{Z}$ ) in the salivary glands, heads, thorax-abdomens, midgut and fat-body of Ae. aegypti females were $\mathrm{Y}=-4.394 \times \log (\mathrm{Z})+49.50$ $\left(R^{2}=0.9985 ;\right.$ salivary glands $) ; Y=-3.985 \times \log (Z)+46.61$ $\left(R^{2}=0.9984 ;\right.$ heads $) ; Y=-3.823 \times \log (Z)+46.49$ $\left(R^{2}=0.9985\right.$; thorax-abdomens $) ; Y=-4.536 \times \log (Z)+46.29$ $\left(\mathrm{R}^{2}=0.9995\right.$; midguts); and $\mathrm{Y}=-4.029 \times \log (\mathrm{Z})+45.68$ $\left(R^{2}=0.9999\right.$; fat-body), respectively. linear regressions of the $\mathrm{Ct}$ value $(\mathrm{Y})$ against $\log$ (viral load, $\mathrm{Z}$ ) in the salivary glands, heads, thorax-abdomens, midgut and fat-body of Ae. albopictus females were $\mathrm{Y}=-3.321 \times \log (\mathrm{Z})+38.66$ $\left(R^{2}=0.9968 ;\right.$ salivary glands $) ; Y=-3.988 \times \log (Z)+41.77$ $\left(R^{2}=0.9943 ;\right.$ heads $) ; Y=-3.993 \times \log (Z)+44.50$ $\left(R^{2}=0.9975\right.$; thorax-abdomens); $\mathrm{Y}=-4.512 \times \log (\mathrm{Z})+47.27$ $\left(R^{2}=0.9991 ;\right.$ midguts $)$; and $Y=-4.130 \times \log (Z)+44.12$ $\left(R^{2}=0.9995\right.$; fat-body), respectively. For each sample, the viral titer was calculated according to the linear regression above.

\section{Wolbachia detection}

The first generation (F1) of Ae. albopictus adults was used to detect Wolbachia infection. DNA was extracted from the mosquitoes used in the previous experiments by the QIAamp ${ }^{\circ}$ DNA Mini Kit (cat. no. 51306, Qiagen, Hilden, Germany). The PCR reaction was conducted as described by previous studies [25]. Two primer pairs (328F, 5'-CCA GCA GAT ACT ATT GCG-3', and 691R, 5' -AAA AAT TAA ACG CTA CTC CA-3'; 183F, 5' -AAG GAA CCG AAG TTC ATG-3' and 691R) were used to amplify and detect Wolbachia surface protein genes (wsp), group A wAlbA (501 bp) and group B $w$ AlbB (379 bp) in this study. Universal primers (12SRNA-Forward, 5' -AAA CTA GCA TTA GAT ACC CTA TTA T-3' and 12SRNA-Reverse, 5'-AAG AGC GAC GGG CGA TGT GT-3') were used to amplify a cDNA fragment of the insect mtDNA (12SRNA gene), as a control to assess the quality of the template DNA extracted from mosquitoes.

\section{Quantification of Wolbachia density}

The density of Wolbachia in the first generation (F1) of Ae. albopictus adults reared at $28{ }^{\circ} \mathrm{C}$ and different temperatures was determined for the $w$ AlbA and $w$ AlbB infections. Real-time PCR was used for the quantification 
of the Wolbachia gene (wAlbA and wAlbB) as described by $[18,26]$. The $w$ AblA and $w$ AlbB gene was normalized to the mosquito housekeeping gene mRpS6 to adjust for different tissues. Primer pairs ( $w$ AlbA, F- $5{ }^{\prime}-$ GGG TTG ATG TTG AAG GAG-3' and R-5'-CAC CAG CTT TTA CTT GAC C-3'; wAlbB, F-5'-CCT TAC CTC CTG CAC AAC AA-3' and R-5'-GGA TTG TCC AGT GGC CTT A-3'; mRpS6, F-5'-AGT TGA ACG TAT CGT TTC CCG CTA C-3' and R-5'-GAA GTG ACG CAG CTT GTG GTC GTC C-3') were used. The qPCR cycling conditions used are as follows: an initial incubation at $90{ }^{\circ} \mathrm{C}$ for $5 \mathrm{~min}$, followed by 45 cycles of amplification at $95{ }^{\circ} \mathrm{C}$ for $10 \mathrm{~s}, 56{ }^{\circ} \mathrm{C}$ for $20 \mathrm{~s}$ and $72{ }^{\circ} \mathrm{C}$ for $20 \mathrm{~s}$ and a melting curve detection and a final cooling step of $40{ }^{\circ} \mathrm{C}$ for $10 \mathrm{~s}$. The relative quantification fold of $\mathrm{Wo}-$ lbachia was calculated using the following formula $2^{\wedge}$ -(ct of $w \mathrm{Alb} / \mathrm{ct}$ of $\mathrm{mRpS} 6$ ).

\section{Statistical analysis}

Statistical analyses were performed with Statistica 10 software (StatSoft, Inc., Tulsa, OK, USA). Initially, we performed a test to compare the five survival curves against dpi for each mosquito species using the nonparametric Kaplan-Meier analysis [27]. If this test revealed significant differences among all curves for each species, we then ran a paired log-rank test to identify which paired curves were different. Mosquitoes that were killed to detect the virus for each dpi category were classified as censored observations [28]. Additionally, a paired log-rank test was used to compare survival against dpi for Wolbachia-infected and Wolbachia-free mosquitoes of Ae. albopictus. Because of the small number of samples tested for each combination, Fisher's exact test was used to test the differences in thoraxabdomen and salivary gland infection rates. The Kolmogorov-Smirnov test was used to compare the overall differences in the entire growth curve of the virus at different temperatures in the thorax-abdomen (data on viral uptake at 0 dpi were excluded), salivary glands, and head samples. Student's $t$ tests were used to detect the differences in virus titers between mosquito species, incubation temperatures and dpi.

\section{Results}

\section{Virus detection in Ae. aegypti}

Infection rates (range $60-100 \%)$ of $\mathrm{F} 1$ field collected Ae. aegypti mosquitoes after oral infection with DENV-1 were unrelated to incubation temperatures (Fisher's exact test, $P>0.05$ ) (Table 1 ). From the 0 dpi data, all female mosquitoes were $100 \%$ infected with no significant difference $(P>0.05)$ in virus titers $\left(10^{2.70} \pm 0.56\right.$ $10^{2.86} \pm 0.40 \mathrm{PFU}$ equivalents $/ \mathrm{ml}$ ) (Fig. 1a). Viral loads were dependent on incubation temperatures (Fig. 1a). The virus growth curves of infected Ae. aegypti at higher temperatures $\left(28\right.$ and $34{ }^{\circ} \mathrm{C}$ ) were not significantly different (Kolmogorov-Smirnov test, $P>0.05$ ) but were significantly different (Kolmogorov-Smirnov test, $P<0.05$ ) from other temperatures $\left(10,16\right.$ and $\left.22{ }^{\circ} \mathrm{C}\right)$. When incubated at $34{ }^{\circ} \mathrm{C}$, the level of viral genomes was significantly (t-test, $t=2.38-4.12, d f=8-11, P<0.05$ ) higher than at $10{ }^{\circ} \mathrm{C}$ and $5-10 \mathrm{dpi}$, at $16{ }^{\circ} \mathrm{C}$ and $5-$ $15 \mathrm{dpi}$ or at $22{ }^{\circ} \mathrm{C}$ and $20 \mathrm{dpi}$. At $22-34{ }^{\circ} \mathrm{C}$, the viral loads showed an increasing trend with a peak at 15 dpi. The peak viral titers at 22,28 and $34{ }^{\circ} \mathrm{C}$ were

Table 1 Mosquito infection rates (\%) with days post-infection (dpi) at different incubation temperatures (number of thoraxabdomen samples testing positive for virus genomes/total number of samples)

\begin{tabular}{|c|c|c|c|c|c|c|}
\hline Species & dpi & $10^{\circ} \mathrm{C}$ & $16^{\circ} \mathrm{C}$ & $22^{\circ} \mathrm{C}$ & $28^{\circ} \mathrm{C}$ & $34^{\circ} \mathrm{C}$ \\
\hline \multirow[t]{7}{*}{ Ae. aegypti } & 0 & $100(10 / 10)$ & $100(10 / 10)$ & $100(10 / 10)$ & $100(10 / 10)$ & $100(10 / 10)$ \\
\hline & 5 & $100(6 / 6)$ & $86(6 / 7)$ & $88(7 / 8)$ & $88(7 / 8)$ & $88(7 / 8)$ \\
\hline & 10 & $100(4 / 4)$ & $100(6 / 6)$ & $88(7 / 8)$ & $100(8 / 8)$ & $88(7 / 8)$ \\
\hline & 15 & & $100(5 / 5)$ & $100(6 / 6)$ & $88(7 / 8)$ & $88(7 / 8)$ \\
\hline & 20 & & & $100(4 / 4)$ & $100(8 / 8)$ & $86(6 / 7)$ \\
\hline & 25 & & & $100(2 / 2)$ & $100(7 / 7)$ & $86(6 / 7)$ \\
\hline & 30 & & & & $100(6 / 6)$ & $60(3 / 5)$ \\
\hline \multirow[t]{7}{*}{ Ae. albopictus } & 0 & $100(10 / 10)$ & $100(10 / 10)$ & $100(10 / 10)$ & $100(10 / 10)$ & $100(10 / 10)$ \\
\hline & 5 & $100(9 / 9)$ & $89(8 / 9)$ & $100(9 / 9)$ & $90(9 / 10)$ & $78(7 / 9)$ \\
\hline & 10 & $88(7 / 8)$ & $44(4 / 9)$ & $75(6 / 8)$ & $90(9 / 10)^{*}$ & $38(3 / 8)^{*}$ \\
\hline & 15 & $57(4 / 7)^{*}$ & $0(0 / 9)^{*}$ & $13(1 / 8)^{*}$ & $67(6 / 9)^{*}$ & $60(3 / 5)$ \\
\hline & 20 & $40(2 / 5)$ & $0(0 / 9)$ & $33(2 / 6)$ & $13(1 / 8)$ & $0(0 / 3)$ \\
\hline & 25 & $25(1 / 4)$ & $0(0 / 8)$ & $20(1 / 5)$ & $14(1 / 7)$ & $0(0 / 3)$ \\
\hline & 30 & $0(0 / 3)$ & $0(0 / 7)$ & $0(0 / 4)$ & $0(0 / 5)$ & $0(0 / 1)$ \\
\hline
\end{tabular}

"Infection rates of Aedes albopictus at $10 \mathrm{dpi}$ with incubation at $28^{\circ} \mathrm{C}$ were significantly higher than those at $34^{\circ} \mathrm{C}$, as determined by Fisher's exact test. Significant differences were also observed at $15 \mathrm{dpi}$ between $10{ }^{\circ} \mathrm{C}$ and $16{ }^{\circ} \mathrm{C}$ and between $28{ }^{\circ} \mathrm{C}$ and 16 or $22^{\circ} \mathrm{C}$ 

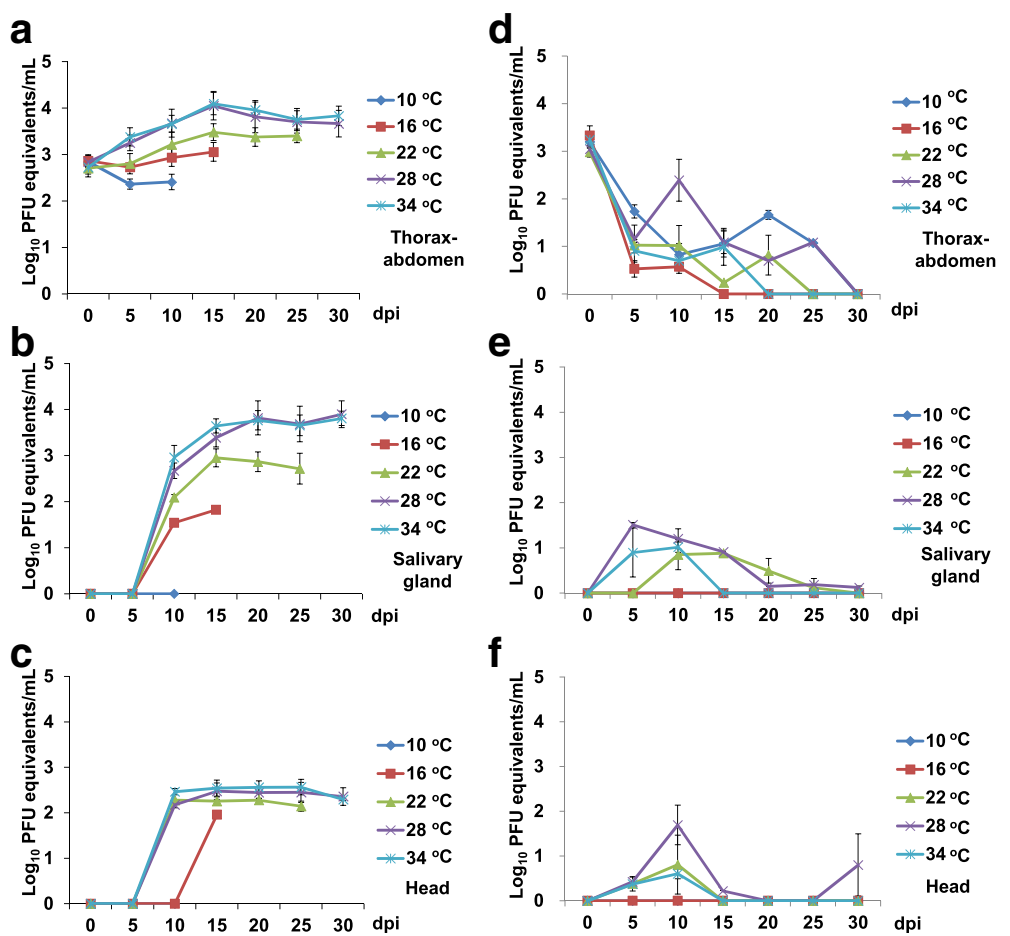

Fig. 1 Virus titers (mean \pm SE) in the thorax-abdomen (a), salivary gland (b) and head (c) samples of infected Aedes aegypti mosquitoes and the thorax-abdomen (d), salivary gland (e) and head (f) samples of infected Aedes albopictus mosquitoes at different incubation temperatures with an initial virus titer of $1.63 \times 10^{7} \mathrm{PFU} / \mathrm{ml}$ (initial $n=10$ for each combination of temperature, dpi, and mosquito species)

$10^{3.49 \pm 0.47}, 10^{4.05 \pm 0.86}$ and $10^{4.09 \pm 0.71}$ PFU equivalents/ml, respectively (Additional file 1: Table S1).

The rate or titer of viral infection of the salivary gland is known as an indicator of transmission potential. After $10 \mathrm{dpi}$, higher salivary gland infection rates (range 25$100 \%)$ at $22-34{ }^{\circ} \mathrm{C}$ were found compared with the lower incubation temperatures (range 0-20\%), although no significant differences were detected (Fisher's exact, $P>0.05$ ) (Table 1 ). In the salivary gland samples of $A e$. aegypti, no viral genomes were detected at $10{ }^{\circ} \mathrm{C}$ or at $0-5$ dpi and $16-34{ }^{\circ} \mathrm{C}$ (Fig. 1b, Table 2). The viral load increased with infection time after $10 \mathrm{dpi}$. The virus growth curves of infected Ae. aegypti at higher temperatures $\left(28\right.$ and $\left.34{ }^{\circ} \mathrm{C}\right)$ were not significantly different from each other (Kolmogorov-Smirnov test, $\mathrm{P}>0.05$ ) but were significantly different (Kolmogorov-Smirnov test, $P<0.05)$ from that at low temperatures $\left(10\right.$, and $\left.16{ }^{\circ} \mathrm{C}\right)$. The growth curve at $22^{\circ} \mathrm{C}$ was not significantly different (Kolmogorov-Smirnov test, $P>0.05$ ) from that at $28{ }^{\circ} \mathrm{C}$ but was significantly different (Kolmogorov-Smirnov test, $P<0.05)$ from that of $34{ }^{\circ} \mathrm{C}$. Significant differences (t-test, $t=2.94-4.44, d f=5, P<0.05$ ) in virus titer were detected at $15 \mathrm{dpi}$ between $16^{\circ} \mathrm{C}$ and higher $\left(28\right.$ or $\left.34{ }^{\circ} \mathrm{C}\right)$ incubation temperatures. Additionally, the viral loads at 15-20 dpi and $34{ }^{\circ} \mathrm{C}$ or at $15 \mathrm{dpi}$ and $28{ }^{\circ} \mathrm{C}$ were significantly higher (t-test, $t=2.43-3.85, d f=6-9, P<0.05$ ) than those at $22{ }^{\circ} \mathrm{C}$. At $16{ }^{\circ} \mathrm{C}$, only viral genomes were
Table 2 Mosquito salivary gland infection rates (\%) with days post-infection (dpi) at different temperatures (number of salivary gland samples testing positive for virus genomes/total number of samples)

\begin{tabular}{lllllll}
\hline Species & $\mathrm{dpi}$ & $10{ }^{\circ} \mathrm{C}$ & $16{ }^{\circ} \mathrm{C}$ & $22^{\circ} \mathrm{C}$ & $28{ }^{\circ} \mathrm{C}$ & $34{ }^{\circ} \mathrm{C}$ \\
\hline Ae. aegypti & 0 & $0(0 / 10)$ & $0(0 / 10)$ & $0(0 / 10)$ & $0(0 / 10)$ & $0(0 / 10)$ \\
& 5 & $0(0 / 6)$ & $0(0 / 7)$ & $0(0 / 8)$ & $0(0 / 8)$ & $0(0 / 8)$ \\
& 10 & $0(0 / 4)$ & $17(1 / 6)$ & $25(2 / 8)$ & $50(4 / 8)$ & $63(5 / 8)$ \\
& 15 & & $20(1 / 5)$ & $83(5 / 6)$ & $88(6 / 8)$ & $88(6 / 8)$ \\
& 20 & & & $100(4 / 4)$ & $63(5 / 8)$ & $57(4 / 7)$ \\
& 25 & & & $100(2 / 2)$ & $57(4 / 7)$ & $57(4 / 7)$ \\
Ae. albopictus & 0 & $0(0 / 10)$ & $0(0 / 10)$ & $0(0 / 10)$ & $0(0 / 10)$ & $0(0 / 10)$ \\
& 5 & $0(0 / 9)$ & $0(0 / 9)$ & $0(0 / 9)$ & $40(4 / 10)$ & $22(2 / 9)$ \\
& 10 & $0(0 / 8)^{\mathrm{a}}$ & $0(0 / 9)^{\mathrm{a}}$ & $75(6 / 8)^{\mathrm{a}}$ & $70(7 / 10)^{\mathrm{a}}$ & $38(3 / 8)$ \\
& 15 & $0(0 / 7)$ & $0(0 / 9)$ & $13(1 / 8)$ & $11(1 / 9)$ & $0(0 / 5)$ \\
& 20 & $0(0 / 5)$ & $0(0 / 9)$ & $33(2 / 6)$ & $13(1 / 8)$ & $0(0 / 3)$ \\
& 25 & $0(0 / 4)$ & $0(0 / 8)$ & $20(1 / 5)$ & $29(2 / 7)$ & $0(0 / 3)$ \\
& 30 & $0(0 / 3)$ & $0(0 / 7)$ & $0(0 / 4)$ & $40(2 / 5)$ & $0(0 / 1)$ \\
\hline
\end{tabular}

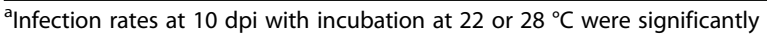
$(P<0.01$ or 0.05$)$ higher than those at 10 or $16^{\circ} \mathrm{C}$, as determined by Fisher's exact test 
detected in one female at 10 and $15 \mathrm{dpi}$ with viral loads of $10^{1.54}$ and $10^{1.82} \mathrm{PFU}$ equivalents $/ \mathrm{ml}$, respectively. At $22^{\circ}$ $\mathrm{C}$, viral genomes were detected in the salivary glands of 2 females at $10 \mathrm{dpi}$ with $10^{2.09} \pm 0.08 \mathrm{PFU}$ equivalents $/ \mathrm{ml}$ of the viral load. The viral loads increased to $10^{2.69} \pm 0.43$, $10^{2.54 \pm 0.31}$, and $10^{2.38} \mathrm{PFU}$ equivalents/ml at 15,20 and $25 \mathrm{dpi}$, respectively, with a salivary gland infection rate range of $83-100 \%$. At 28 and $34{ }^{\circ} \mathrm{C}$, viral genomes were first detected in the salivary gland samples at $10 \mathrm{dpi}$ and viral loads of $10^{2.67 \pm 0.33}$ and $10^{2.96 \pm 0.52}$ PFU equivalents/ $\mathrm{ml}$ (salivary gland infection rates $=50-63 \%$ ). At $15-30$ $\mathrm{dpi}$, the viral loads detected were between $10^{3.38 \pm 0.49}$ and $10^{3.89} \pm 0.58$ PFU equivalents $/ \mathrm{ml}$ with a salivary gland infection range of $57-88 \%$. In the head samples, viral genomes were first detected at $16{ }^{\circ} \mathrm{C}$ and $15 \mathrm{dpi}$ with a quantity of $10^{1.95} \mathrm{PFU}$ equivalents/ml (Fig. 1c). At 22-34 ${ }^{\circ}$ $\mathrm{C}$, virus genomes were first detected at $10 \mathrm{dpi}$ and were maintained as constant titers thereafter. Viral titers of viruses grown at low $\left(10\right.$ or $\left.16{ }^{\circ} \mathrm{C}\right)$ and high $\left(28\right.$ or $\left.34{ }^{\circ} \mathrm{C}\right)$ incubation temperatures at $10 \mathrm{dpi}$ were significantly different (t-test, $t=3.05-55.33, d f=5-8, P<0.05$ ).

\section{Virus detection in Ae. albopictus}

Infection rates in Ae. albopictus at 10 dpi with incubation at $28{ }^{\circ} \mathrm{C}$ were significantly (Fisher's exact test, $P<0.05)$ higher than at $34{ }^{\circ} \mathrm{C}$. Significant differences (Fisher's exact test, $P<0.05$ ) were also found at $15 \mathrm{dpi}$ between $10{ }^{\circ} \mathrm{C}$ and $16{ }^{\circ} \mathrm{C}$ and between $28{ }^{\circ} \mathrm{C}$ and 16 or $22{ }^{\circ} \mathrm{C}$ (Fig. 1d). No viruses were detected in the salivary gland (Fig. 1e) or head samples (Fig. 1f) at $10-16{ }^{\circ} \mathrm{C}$ or at $0-5 \mathrm{dpi}$ and $22-34{ }^{\circ} \mathrm{C}$. The highest salivary gland infection rates $(38-75 \%)$ were detected at 10 dpi for $22-$ $34{ }^{\circ} \mathrm{C}$ incubation temperatures and the rates at 22 or $28{ }^{\circ} \mathrm{C}$ were significantly (Fisher's exact test, $P<0.05$ ) higher than those at lower temperatures $\left(10\right.$ or $\left.16^{\circ} \mathrm{C}\right)$. From the 0 dpi data, all female mosquitoes were $100 \%$ infected without significant difference (t-test, $t=0-1.56$, $d f=18, P>0.05)$ in virus titers $\left(10^{2.98} \pm 0.30-10^{3.33} \pm 0.64\right.$ PFU equivalents $/ \mathrm{ml}$ ) (Fig. 1d). Viral genomes were detected in the thorax-abdomen samples with low titers $\left(10^{0.23}-10^{2.39} \pm 1.31 \mathrm{PFU}\right.$ equivalents $\left./ \mathrm{ml}\right)$ at all incubation temperatures $\left(10-34{ }^{\circ} \mathrm{C}\right)$ after $10 \mathrm{dpi}$ with largely varied infection rates (0-90\%) (Table 1). Viral genomes were first detected at $10 \mathrm{dpi}$ and $22{ }^{\circ} \mathrm{C}$ and earlier (5 dpi) at higher temperatures $\left(28\right.$ or $34{ }^{\circ} \mathrm{C}$ ) with low titers $\left(10^{0.12} \pm 0.05-10^{1.51} \pm 0.31 \mathrm{PFU}\right.$ equivalents $\left./ \mathrm{ml}\right)$. In the head samples, viral genomes were detected at 5-30 dpi with low titers $\left(10^{0.22}-10^{1.69} \pm 1.32 \mathrm{PFU}\right.$ equivalents $\left./ \mathrm{ml}\right)$ in $22-34{ }^{\circ} \mathrm{C}$ environments.

\section{Impact of Wolbachia on Ae. albopictus}

Since lower viral replication was found in Ae. albopictus compared with Ae. aegypti mosquitoes, we analyzed the infection rate of Wolbachia in the tested Ae. albopictus mosquitoes. Interestingly, the results showed that 92.897.2\% of Ae. albopictus mosquitoes were co-infected with Wolbachia group A (wAlbA) and group B (wAlbB) (Table 3). Only 1.4-2.9\% of females were not infected with Wolbachia. To determine whether Wolbachia in Ae. albopictus affects DENV-1 replication, we generated Wolbachia-free mosquitoes with tetracycline treatment in 3 generations (Additional file 1: Figure S1). We fed Wolbachia-free mosquitoes with a blood-meal with the same DENV-1 and then incubated them at $28{ }^{\circ} \mathrm{C}$, which has the best viral load among the tested temperatures. The survival trend of Wolbachia-free Ae. albopictus mosquitoes fed with DENV-1 significantly (log-rank test, $P<0.05)$ decreased compared with Wolbachia-infected mosquitoes (Fig. 2a). The infection rate in Wolbachiafree Ae. albopictus mosquitoes increased from 5 to 20 dpi and then slightly dropped (Fig. 2b). The infection rate in the Wolbachia-infected mosquitoes was significantly higher at 5 (Fisher's exact test, $P<0.01$ ) and 10 dpi (Fisher's exact test, $P<0.05$ ) than in the Wolbachiafree mosquitoes. We also found the same transmission trend (increasing from 5 to $20 \mathrm{dpi}$ and then dropping slightly) in the Wolbachia-free mosquitoes. The salivary gland infection rate of the Wolbachia-free mosquitoes was significantly (Fisher's exact test, $P<0.05$ ) higher at 15 and 20 dpi compared to Wolbachia-infected mosquitoes at $28{ }^{\circ} \mathrm{C}$ (Fig. 2c). We also found that the salivary glands of Wolbachia-infected mosquitoes became infected earlier at 5 dpi than those of the Wolbachia-free mosquitoes at the margin of significance (Fisher's exact test, $P=0.0542$ ).

The virus growth curves in thorax-abdomen and salivary gland samples of Wolbachia-free Ae. albopictus and Ae. aegypti were significantly different from those of Wolbachia-infected Ae. albopictus (Kolmogorov-Smirnov test, $P<0.05$ ) but not significantly different (Kolmogorov-Smirnov test, $P>0.05)$ from each other. Viral genomes were first detected in the thorax-abdomen, salivary gland, and head samples of the Wolbachia-free mosquitoes at $10 \mathrm{dpi}$ with viral titers $10^{2.29} \pm 0.37$, $10^{1.02} \pm 0.12$ and $10^{1.52 \pm 0.26}$ PFU equivalents $/ \mathrm{ml}$, respectively (Fig. 2d-f). The virus titer in the thorax-abdomen samples peaked $\left(10^{4.26 \pm 0.58} \mathrm{PFU}\right.$ equivalents $\left./ \mathrm{ml}\right)$ at 15 dpi and remained high (Fig. 2d). Virus titers of Wolbachia-free mosquitoes were significantly higher at 15-30 dpi (t test, $P<0.05$ ) and lower at $5 \mathrm{dpi}$ (t-test, $t=3.46$, $d f=17, P<0.01)$ compared with the Wolbachia-infected mosquitoes. Viral genomes were detected in the salivary gland samples at $10-30 \mathrm{dpi}$ with increasing titers $\left(10^{1.02} \pm 0.12-10^{3.11} \pm 0.45\right.$ PFU equivalents $\left./ \mathrm{ml}\right)$ (Fig. 2e). Virus titers of Wolbachia-free mosquitoes were significantly higher at 20-30 dpi (t-test, $t=5.00-14.01$, df $=2-$ $3, P<0.05)$ and lower at $5 \mathrm{dpi}(\mathrm{t}$-test, $t=48.10, d f=11$, $P<0.01)$ compared with the Wolbachia-infected 
Table 3 Wolbachia infection in the tested Aedes albopictus mosquitoes at different temperatures

\begin{tabular}{|c|c|c|c|c|c|c|c|c|c|}
\hline \multirow{2}{*}{$\begin{array}{l}\text { Incubation } \\
\text { temperatures }\end{array}$} & \multirow{2}{*}{$\begin{array}{l}\text { No. of } \\
\text { mosquitoes } \\
\text { tested }\end{array}$} & \multicolumn{2}{|c|}{ Non-infected } & \multicolumn{2}{|c|}{ wAlbA only } & \multicolumn{2}{|c|}{ wAlbB only } & \multicolumn{2}{|c|}{ Coinfection with $\mathrm{A}$ and $\mathrm{B}$} \\
\hline & & $n$ & $\%$ & $n$ & $\%$ & $n$ & $\%$ & $n$ & $\%$ \\
\hline $10^{\circ} \mathrm{C}$ & 70 & 1 & 1.4 & 1 & 1.4 & 0 & 0 & 68 & 97.2 \\
\hline $16^{\circ} \mathrm{C}$ & 70 & 2 & 2.9 & 2 & 2.9 & 1 & 1.4 & 65 & 92.8 \\
\hline $22^{\circ} \mathrm{C}$ & 70 & 2 & 2.9 & 1 & 1.4 & 1 & 1.4 & 66 & 94.3 \\
\hline $28^{\circ} \mathrm{C}$ & 70 & 1 & 1.4 & 1 & 1.4 & 0 & 0 & 68 & 97.2 \\
\hline $34{ }^{\circ} \mathrm{C}$ & 70 & 2 & 2.9 & 3 & 4.3 & 0 & 0 & 65 & 92.8 \\
\hline
\end{tabular}

mosquitoes. Virus titers in head samples were detected from 10 to $30 \mathrm{dpi}$ at quantities of $10^{1.52} \pm 0.26$ $10^{2.22} \pm 0.26$ PFU equivalents/ml (Fig. $2 \mathrm{f}$ and Additional file 1: Table S2). The virus titers of Wolbachia-free mosquitoes were significantly higher (t test, $P<0.01$ ) at $15-$ $25 \mathrm{dpi}$ and lower (t-test, $t=2.51, d f=17, P<0.05$ ) at 5 dpi compared with those of the Wolbachia-infected mosquitoes.

To minimize the impact of the antibiotic on mosquito microflora, the eighth generation (F8, tetracycline was stopped at F6) was also evaluated as the Wolbachia-free mosquitoes at $28{ }^{\circ} \mathrm{C}$ condition. Furthermore, insect midgut and fat-body is highly related to the immune defense system for pathogens. We also detected the dengue viral genome copy in these two samples. High viral genome copies were detected in midgut samples, followed by fatbody, salivary gland, thorax-abdomen, and head samples in Wolbachia-free (F8) from 10 to 30 dpi (Fig. 3a). Only few viruses could be detected in all samples of Wolbachia-infected (F1) Ae. albopictus from 10 to $20 \mathrm{dpi}$, and no virus could be detected after 25 dpi (Fig. 3b).

Wolbachia can induce density-dependent inhibition of dengue virus in Aedes mosquitoes, and its density is temperature sensitive. Wolbachia density was also measured in different tissues at different temperatures in Wolbachia-infected F1 Ae. albopictus (Fig. 4). wAlbB (Fig. 4a) had higher densities than wAlbA (Fig. 4a). The relative density of $w \mathrm{AlbA}$ and $w \mathrm{AlbB}$ (ratio of $w \mathrm{AlbB}$ or $w$ AlbA to host rps6 genomes) was commonly found in thorax-abdomen samples (0.1104 \pm 0.0179 and

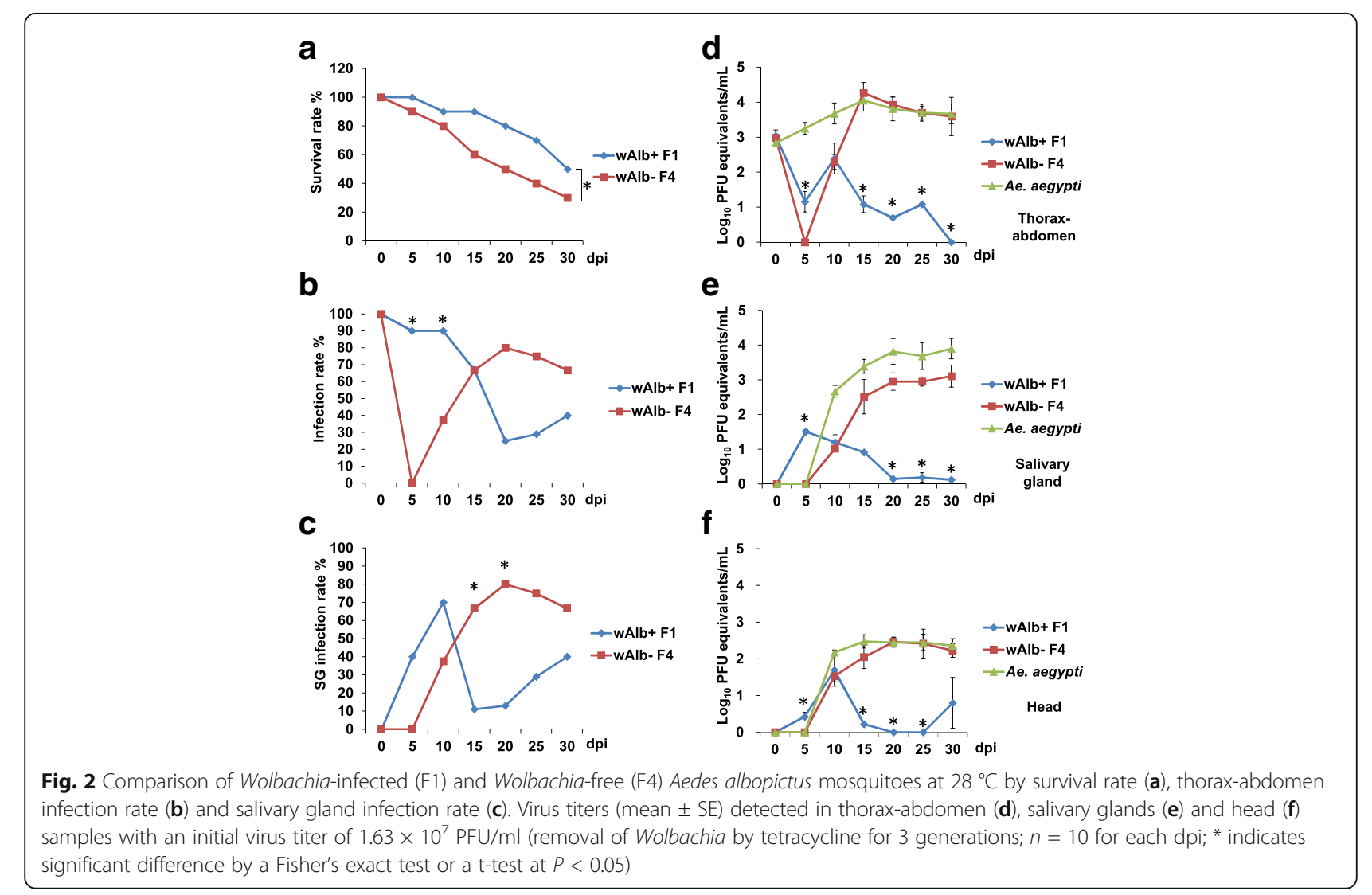




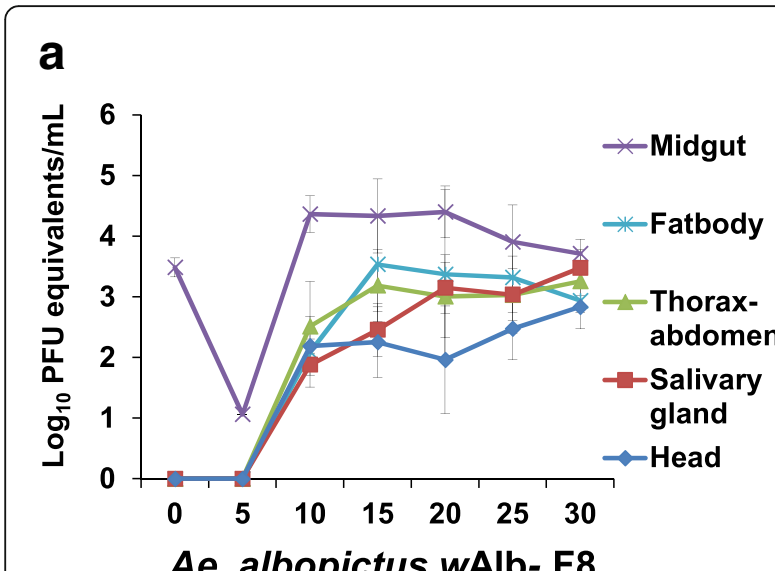

b

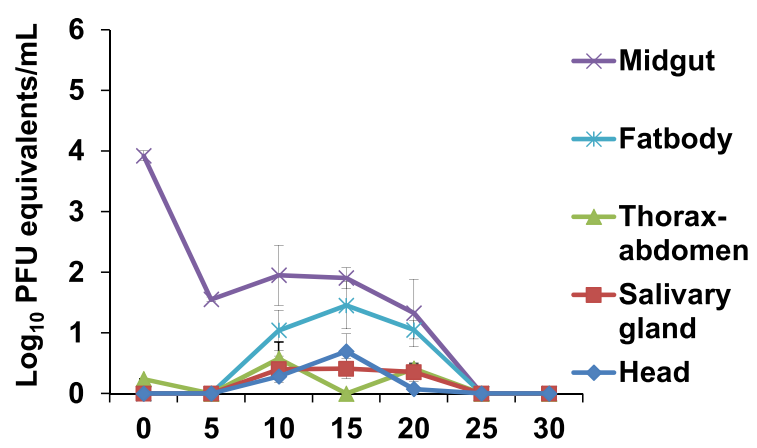

Ae. albopictus wAlb+F1

Fig. 3 Virus titers (mean \pm SE) in the thorax-abdomen, salivary gland, head, midgut and fat-body samples of Wolbachia-free (F8) (a), and Wolbachia-infected (F1) (b) of Aedes albopictus with an initial virus titer of $1.63 \times 10^{7} \mathrm{PFU}$ per $\mathrm{ml}$ (removal of Wolbachia by tetracycline for 5 generations and recovery for 2 generations; $n=10$ for each dpi)

$0.6048 \pm 0.0617$, respectively), followed by fat-body $(0.0052 \pm 0.0017$ and $0.0652 \pm 0.0103$, respectively $)$ and midgut samples $(0.0003 \pm 0.0002$ and $0.0008 \pm 0.0001$, respectively). For thorax-abdomen samples, the temperature-dependent effect from 10 to $28^{\circ} \mathrm{C}$ on Wolbachia density was found in both strains. The results showed that both $w$ AlbA (Fig. 4a) and wAlbB (Fig. 4b) were significantly located in thorax-abdomen compared to other tissues and had the highest density at the $28{ }^{\circ} \mathrm{C}$ rearing condition. At $16^{\circ} \mathrm{C}$ and $22^{\circ} \mathrm{C}$, Wolbachia density was also detected more than at $10{ }^{\circ} \mathrm{C}$ and $34{ }^{\circ} \mathrm{C}$. Additionally, the density of wAlbB was higher than that of wAlbA in all tissues of Ae. albopictus (2.4-6.3 times in thorax-abdomen samples and over 12.4 times in the fat-body).

Survival rates of DENV-1-infected Ae. aegypti and Ae. albopictus mosquitoes

The mosquito survival trends of infected Ae. aegypti were significantly different $\left(\chi^{2}=28.8, d f=4, P=0.00001\right)$

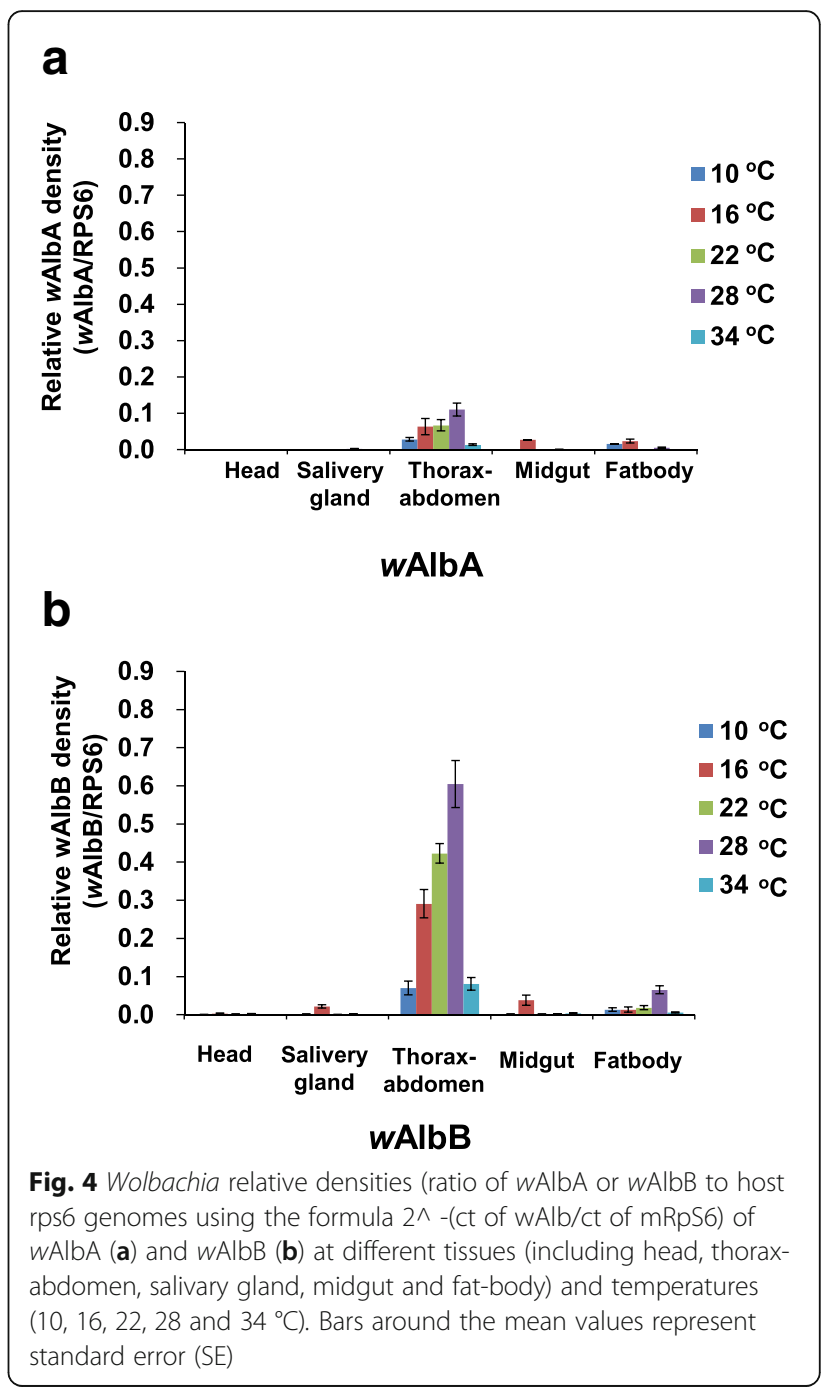

among the 5 incubation temperatures (Fig. 5a). Mosquitoes survived significantly better (log-rank test, $P<0.01$ ) at 28 and $34{ }^{\circ} \mathrm{C}$. No difference (log-rank test, $P>0.05$ ) was found between these two incubation temperatures. The mosquito survival rate of infected Ae. aegypti at $10^{\circ} \mathrm{C}$ was $40 \%$ at $10 \mathrm{dpi}$, which fell to 0 at $15 \mathrm{dpi}$ (Fig. 5a). At $16{ }^{\circ} \mathrm{C}$, the survival rates slightly increased; the survival rates were $50 \%$ and $0 \%$ at $15 \mathrm{dpi}$ and $20 \mathrm{dpi}$, respectively. At $22{ }^{\circ} \mathrm{C}$, the survival rates were $60 \%, 20 \%$ and $0 \%$ at 15 , 25 and $30 \mathrm{dpi}$, respectively. At $28{ }^{\circ} \mathrm{C}$ and $34{ }^{\circ} \mathrm{C}$, the survival rates were $80 \%$ and $50-60 \%$ at 25 and $30 \mathrm{dpi}$, respectively.

The mosquito survival trend of infected Ae. albopictus mosquitoes was significantly different $\left(\chi^{2}=15.8, d f=4\right.$, $P=0.00337$ ) among the 5 incubation temperatures (Fig. $5 b)$. Mosquitoes survived significantly better (log-rank test, test statistic $=2.28-4.21, P<0.05)$ at 16 or $28^{\circ} \mathrm{C}$ than at other incubation temperatures, but no difference (logrank test, test statistic $=0.73, P>0.05$ ) was found between 


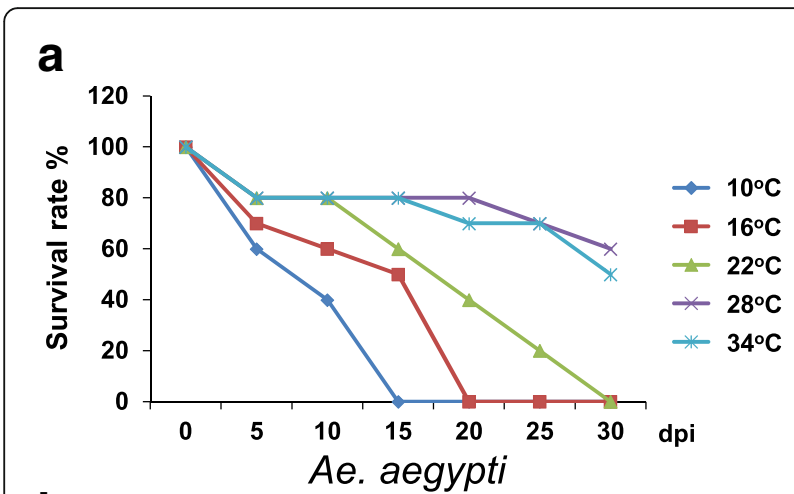

b

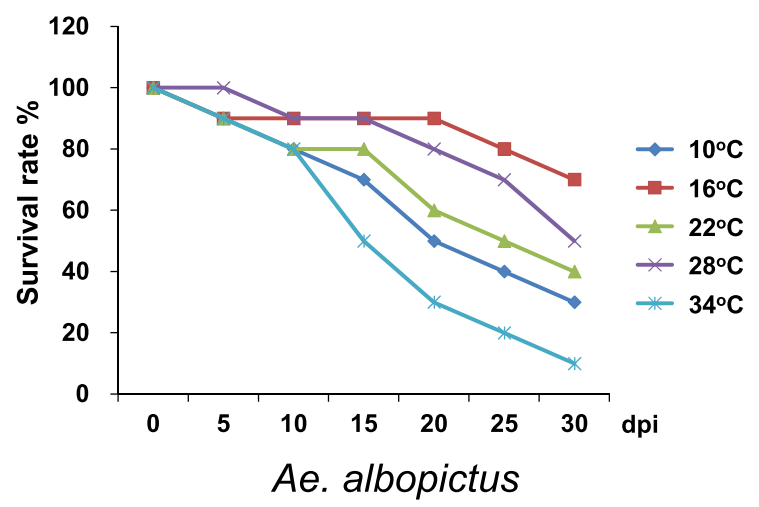

Fig. 5 Mosquito survival rates of Aedes aegypti (a) and Aedes albopictus (b) with days post-infection (dpi) at different incubation temperatures ( $n=10$ for each combination of temperature, dpi, and mosquito species)

these 2 temperatures. Additionally, no differences (logrank test, test statistic $=1.64, P>0.05$ ) were found in the trend of survival curves between 22 and $28{ }^{\circ} \mathrm{C}$. At $16{ }^{\circ} \mathrm{C}$, the survival rates decreased to $90 \%, 80 \%$, and $70 \%$ at 10 , 20 and $30 \mathrm{dpi}$, respectively. At 22 and $28{ }^{\circ} \mathrm{C}$, the survival rates were $80-88 \%, 60-80 \%$ and $40-50 \%$ in the same 3 periods. At $34{ }^{\circ} \mathrm{C}$, the mosquitoes showed the poorest survival, with survival rates of $10 \%$ at $30 \mathrm{dpi}$. In addition, the Wolbachia-free Ae. albopictus mosquitoes survived significantly better (log-rank test, test statistic $=-2.51, P<0.05$ ) than the Wolbachia-infected mosquitoes (Fig. 2a).

\section{Discussion}

Our data confirmed the temperature effects on virus replication as in previous studies, but we detected the native Wolbachia effect on Ae. albopictus vector competence by increasing DENV replication in Wolbachiacured Ae. albopictus. Aedes aegypti mosquitoes survived better, and virus titers were significantly higher at high temperature $\left(28\right.$ or $\left.34{ }^{\circ} \mathrm{C}\right)$. However, Ae. albopictus mosquitoes lived longer at 16 and $28{ }^{\circ} \mathrm{C}$, and virus titers were significantly higher at 22 and $28{ }^{\circ} \mathrm{C}$ (Fig. 1a, b, d, e and Fig. 5). Viruses were first detected at $10 \mathrm{dpi}$ in salivary glands and head tissues in Ae aegypti and 5 or 10 dpi in Ae. albopictus (Fig. 1b-d, f). Wolbachia infections were detected in up to $97 \%$ of the tested Ae. albopictus mosquitoes (Table 3). We concluded that in southern Taiwan, Ae aegypti is the main vector of dengue and Ae. albopictus has an insignificant role due to the high native Wolbachia infection in the local mosquito population. Therefore, the elimination or a significant reduction of $A e$. aegypti populations is an effective method for dengue prevention in southern Taiwan, where Ae aegypti and Ae. albopictus coexist.

The EIP is known to be temperature dependent [6, 25]. Within viable temperature ranges, a higher temperature is associated with a shorter EIP. In our study, when incubation temperatures were greater than $22{ }^{\circ} \mathrm{C}$, the EIP in $A e$ aegypti for the dengue virus was between 5 and 10 days, regardless of the incubation temperature. These results were confined to our mosquito collection setting at $5 \mathrm{dpi}$ intervals with a fixed virus uptake quantity, which was not sensitive for the detection of the EIP temperaturedependent trend in Ae. aegypti. However, this trend was clearly detected in the Ae. albopictus species, in which EIPs (between 0 and 5 days) were shorter at higher temperatures (28 and $34{ }^{\circ} \mathrm{C}$ ) and longer (between 5 and 10 days) at $22{ }^{\circ} \mathrm{C}$ (Fig. 1e). The thresholds for dengue transmission in constant temperatures were $13{ }^{\circ} \mathrm{C}$ [29] and $35^{\circ} \mathrm{C}[6,30]$, which was consistent with our results in Ae. aegypti (Fig. 1b, c), no virus particles in salivary glands and head samples were found at $10{ }^{\circ} \mathrm{C}$ ). Recent studies have simulated diurnal field temperature fluctuations to show that this factor could shorten the extrinsic incubation period [31-33].

In our study, the survival rates of Ae. albopictus mosquitoes infected with Wolbachia were significantly better (Fig. 5). Although the study of Mousson et al. showed the same survival trend, no significant difference was detected [14]. This outcome might be due the different virus strain infected (DENV-1 vs DENV-2) or mosquito strain. This study found that local Ae. albopictus has a high percentage of infection with $w$ AlbA and $w$ AlbB (Table 3). In Taiwan, $51.7 \%$ of mosquitoes in 29 species were infected with Wolbachia, and co-infections with $w$ AlbA and $w$ AlbB have also been recorded [21]. However, none of the Ae. aegypti mosquitoes (the first generation of field collected larvae, $n=32$ ) were infected with Wolbachia in this study.

Wolbachia-free (F4 and F8) Ae. albopictus mosquitoes showed sufficient vector competence after orally fed dengue virus compared to original mosquitoes (F1) and Ae. aegypti, indicating that Wolbachia infection may play a role in Ae. albopictus transmission of the dengue virus. In our study, we showed the reduction of virus load in all tissue samples (Figs. 2, 3), which was inconsistent with other natural Wolbachia infection studies. In these studies, either no native Wolbachia effect [18] or only 
virus transmission reduction [14] was found in dengue virus in Ae. albopictus mosquitoes.

Altogether, we showed that low temperatures limit the vector competence of local Ae. aegypti and Ae. albopictus populations in the transmission of DENV-1. Furthermore, the highly native Wolbachia infection was able to reduce viral titers and limit the transmission of DENV-1 in the local Ae. albopictus population.

\section{Conclusions}

In southern Taiwan, Ae. aegypti is the main vector of dengue and Ae. albopictus has a non-significant role in the transmission of dengue virus due to the high prevalence of Wolbachia infection in the local mosquito population of southern Taiwan.

\section{Additional file}

Additional file 1: Table S1. Details of the virus titers of tested F1 mosquitoes. Table S2. Details of the virus titers of tested Wolbachia free F4 mosquitoes. Figure S1. Generation of the Wolbachia-free Ae. albopictus mosquitoes (DOCX $112 \mathrm{~kb}$ )

\section{Acknowledgements}

Not applicable.

\section{Funding}

This study was supported by scientific research grants from the Centers for Disease Control, Taiwan, in 2015-2016 (MOHW104-CDC-C-315-000117 and MOHW105-CDC-C-315-123,115).

\section{Availability of data and materials}

All data generated or analyzed during this study are included in this published article and its additional information files.

\section{Authors' contributions}

$\mathrm{CHT}, \mathrm{THC}$, and HJT conceptualized the study, conducted data analysis and manuscript preparation; CHT, THC, and CL conducted field work; PYS and $\mathrm{CLS}$ provided the virus. All authors read and approved the final manuscript.

\section{Ethics approval and consent to participate}

Human blood collected and used for preparation of the feeding mixtures had written consent of the two donors and did not require IRB censor according to IRB committee of CDC Taiwan. The dengue virus serotype 1 (DENV-1) strain ( $\mathrm{H1030440)}$ was originally isolated from a patient during the 2014 outbreak in Kaohsiung [19]. The study protocol by Chang et al. [19] was reviewed and approved by the Taiwan CDC Institutional Review Board (IRB, 103107\#1). The informed consent requirement was waived by the Board. The virus used in this study had been passaged in Aedes albopictus C6/36 cells to generate sufficiently high titer for infection. Virus stocks were titrated using plaque assays to a titer of $1.63 \times 107$ plaque forming units (PFU)/ml. Virus usage on mosquitoes did not require IRB censor according to IRB committee of CDC Taiwan. Virus strains were analyzed anonymously in this study.

\section{Consent for publication}

Not applicable.

\section{Competing interests}

The authors declare that they have no competing interests.

\section{Publisher's Note}

Springer Nature remains neutral with regard to jurisdictional claims in published maps and institutional affiliations.

\section{Author details}

'Center for Diagnostics and Vaccine Development, Centers for Disease Control, Taipei 11561TaiwanRepublic of China. ${ }^{2}$ Present address: Graduate Institute of Biomedical Sciences, Chang Gung University, Kwei-San, Tao-Yuan 33332, Taiwan.

Received: 3 May 2017 Accepted: 23 October 2017

Published online: 07 November 2017

\section{References}

1. Khasnis AA, Nettleman MD. Global warming and infectious disease. Arch Med Res. 2005;36:689-96.

2. Gubler DJ. Dengue, urbanization and globalization: the unholy trinity of the 21st century. Trop Med Health. 2011;39(4 Suppl):3-11.

3. Bhatt S, Gething PW, Brady OJ, Messina JP, Farlow AW, Moyes CL, et al. The global distribution and burden of dengue. Nature. 2013;496(7446):504-7.

4. Brady OJ, Gething PW, Bhatt S, Messina JP, Brownstein JS, Hoen AG, et al. Refining the global spatial limits of dengue virus transmission by evidencebased consensus. PLoS Negl Trop Dis. 2012;6(8):e1760.

5. Lin C, Wang CY, Teng HJ. The study of dengue vector distribution in Taiwan from 2009 to 2011. Taiwan Epi Bull. 2014;30:304-9.

6. Watts DM, Burke DS, Harrison BA, Whitmire RE, Nisalak A. Effect of temperature on the vector efficiency of Aedes aegypti for dengue 2 virus. Am J Trop Med Hyg. 1987;36(1):143-52.

7. Barbazan P, Guiserix M, Boonyuan W, Tuntaprasart W, Pontier D, Gonzalez JP. Modelling the effect of temperature on transmission of dengue. Med Vet Entomol. 2010;24(1):66-73.

8. Halstead SB. Dengue virus-mosquito interactions. Annu Rev Entomol. 2008; 53:273-91.

9. Chan M, Johansson MA. The incubation periods of dengue viruses. PLoS One. 2012;7(11):e50972.

10. Salazar MI, Richardson JH, Sanchez-Vargas I, Olson KE, Beaty BJ. Dengue virus type 2: replication and tropisms in orally infected Aedes aegypti mosquitoes. BMC Microbiol. 2007;7:9.

11. Anderson JR, Rico-Hesse R. Aedes aegypti vectorial capacity is determined by the infecting genotype of dengue virus. Am J Trop Med Hyg. 2006;75(5):886-92.

12. Alto BW, Reiskind MH, Lounibos LP. Size alters susceptibility of vectors to dengue virus infection and dissemination. Am J Trop Med Hyg. 2008;79(5): 688-95.

13. Walker T, Johnson PH, Moreira LA, Iturbe-Ormaetxe I, Frentiu FD, McMeniman CJ, et al. The wMel Wolbachia strain blocks dengue and invades caged Aedes aegypti populations. Nature. 2011;476(7361):450-3.

14. Mousson L, Zouache K, Arias-Goeta C, Raquin V, Mavingui P, Failloux AB. The native Wolbachia symbionts limit transmission of dengue virus in Aedes albopictus. PLoS Negl Trop Dis. 2012;6(12):e1989.

15. Mains JW, Brelsfoard CL, Rose RI, Dobson SL. Female adult Aedes albopictus suppression by Wolbachia-infected male mosquitoes. Sci Rep. 2016;6:33846.

16. Ye YH, Carrasco AM, Dong Y, Sgro CM, McGraw EA. The effect of temperature on Wolbachia-mediated dengue virus blocking in Aedes aegypti. Am J Trop Med Hyg. 2016;94(4):812-9.

17. Mousson L, Martin E, Zouache K, Madec Y, Mavingui P, Failloux AB. Wolbachia modulates chikungunya replication in Aedes albopictus. Mol Ecol. 2010;19(9):1953-64

18. Lu P, Bian G, Pan X, Xi Z. Wolbachia induces density-dependent inhibition to dengue virus in mosquito cells. PLoS Negl Trop Dis. 2012;6(7):e1754.

19. Chang SF, Yang CF, Hsu TC, CL S, Lin CC, Shu PY. Laboratory-based surveillance and molecular characterization of dengue viruses in Taiwan, 2014. Am J Trop Med Hyg. 2016;94(4):804-11.

20. $\mathrm{HH}$ W, Wang $C Y$, Teng HJ, Lin C, LC L, Jian SW, et al. A dengue vector surveillance by human population-stratified ovitrap survey for Aedes (Diptera: Culicidae) adult and egg collections in high dengue-risk areas of Taiwan. J Med Entomol. 2013;50(2):261-9.

21. Tsai KH, Lien JC, Huang CG, WJ W, Chen WJ. Molecular (sub) grouping of endosymbiont Wolbachia infection among mosquitoes of Taiwan. J Med Entomol. 2004;41(4):677-83.

22. Dobson SL, Rattanadechakul WA. Novel technique for removing Wolbachia infections from Aedes albopictus (Diptera: Culicidae). J Med Entomol. 2001; 38(6):844-9.

23. Ooi Y, Hayashi A, Aoki H, Eda J, Hamada M, Imura S, et al. Viral titers in the sera of dengue patients among travelers at the Quarantine Station of Kansai international airport. Jpn J Infect Dis. 2008;61(4):329-30. 
24. Shu PY, Chang SF, Kuo YC, Yueh YY, Chien LJ, Sue CL, et al. Development of group- and serotype-specific one-step SYBR green Ibased real-time reverse transcription-PCR assay for dengue virus. J Clin Microbiol. 2003;41(6):2408-16

25. Zhou W, Rousset F, O'Neil S. Phylogeny and PCR-based classification of Wolbachia strains using wsp gene sequences. Proc Biol Sci. 1998;265(1395): 509-15.

26. Ross PA, Endersby NM, Hoffmann AA. Costs of three Wolbachia infections on the survival of Aedes aegypti larvae under starvation conditions. PLoS Negl Trop Dis. 2016;10(1):e0004320

27. Christiansen-Jucht C, Parham PE, Saddler A, Koella JC, Basanez MG. Temperature during larval development and adult maintenance influences the survival of Anopheles gambiae s.s. Parasit Vectors. 2014;7:489.

28. Kaplan EL, Meier P. Non-parametric estimation from incomplete observations. J Am Stat Assoc. 1958:53(282):457-81.

29. McLean DM, Clarke AM, Coleman JC, Montalbetti CA, Skidmore AG, Walters TE, Wise R. Vector capability of Aedes aegypti mosquitoes for California encephalitis and dengue viruses at various temperatures. Can J Microbiol. 1974;20(2):255-62.

30. Carrington LB, Armijos MV, Lambrechts L, Scott TW. Fluctuations at a low mean temperature accelerate dengue virus transmission by Aedes aegypti. PLoS Negl Trop Dis. 2013;7(4):e2190.

31. Carrington LB, Seifert SN, Armijos MV, Lambrechts L, Scott TW. Reduction of Aedes aegypti vector competence for dengue virus under large temperature fluctuations. Am J Trop Med Hyg. 2013;88(4):689-97.

32. Carrington LB, Seifert SN, Willits NH, Lambrechts L, Scott TW. Large diurnal temperature fluctuations negatively influence Aedes aegypti (Diptera: Culicidae) life-history traits. J Med Entomol. 2013;50(1):43-51.

33. Lambrechts L, Paaijmans KP, Fansiri T, Carrington LB, Kramer LD, Thomas MB, Scott TW. Impact of daily temperature fluctuations on dengue virus transmission by Aedes aegypti. Proc Natl Acad Sci USA. 2011;108(18):7460-5.

\section{Submit your next manuscript to BioMed Central and we will help you at every step:}

- We accept pre-submission inquiries

- Our selector tool helps you to find the most relevant journal

- We provide round the clock customer support

- Convenient online submission

- Thorough peer review

- Inclusion in PubMed and all major indexing services

- Maximum visibility for your research

Submit your manuscript at www.biomedcentral.com/submit 